\title{
ECHOCARDIOGRAPHIC ASSESSMENT OF HYPERTENSIVE CHANGES IN ELDERLY PATIENTS OF ISOLATED SYSTOLIC HYPERTENSION WITH SPECIAL REFERENCE TO CARDIOVASCULAR COMPLICATIONS
}

\author{
BIJAYA KUMAR BEHERA ${ }^{1 *}$, RAKESH MOHANTY ${ }^{1}$, SUKANTA KUMAR JENA ${ }^{2}$, SUSANTA SEKHAR BEHERA ${ }^{1}$
}

${ }^{1}$ Department of General Medicine, MKCG Medical College and Hospital, Berhampur, Odisha, India. ${ }^{2}$ Department of Radiodiagnosis, MKCG Medical College and Hospital, Berhampur, Odisha, India. Email: drbkbehera@gmail.com

Received: 17 December 2020, Revised and Accepted: 12 March 2021

ABSTRACT

Objective: The objective of the study was to assess the echocardiographic changes and cardiovascular complications in patients with isolated systolic hypertension (ISH).

Methods: This was an observational cross-sectional study done in the Departments of General Medicine, Cardiology, and Radiodiagnosis of MKCG Medical College and Hospital, Berhampur, Odisha, India. Seventy patients above the age of 65 years with systolic blood pressure (BP) $\geq 140 \mathrm{~mm}$ $\mathrm{Hg}$ and diastolic BP $<90 \mathrm{~mm} \mathrm{Hg}$, without any secondary causes of hypertension and antihypertensive drug therapy were selected for this study. Echocardiography and electrocardiography studies were implemented for demonstrating the development of cardiovascular complications.

Results: Of 70 cases ( 41 males and 29 females), 64.3\% were asymptomatic and 35.7\% were symptomatic, with palpitation being the major symptom, 40\% (28 cases) developed retinopathy, 45.71\% developed increased left ventricular mass index ( $\mathrm{p}=0.04), 18.57 \%$ had increased in $\mathrm{LV}$ volume $\left(>90 \mathrm{ml} / \mathrm{m}^{2}\right), 30 \%$ cases had regional wall motion abnormalities, $27.1 \%$ had reduced ejection fraction $(<56 \%)$, and $52.66 \%$ showed LA enlargement in this study ( $\mathrm{p}=0.048$ ). Doppler measurements of diastolic filling were significant in patients with ISH with higher peak atrial velocity (A wave) of $79.71 \pm 11.79 \mathrm{~cm} / \mathrm{s}$ and a lower ratio of peak early to atrial velocity of $0.82 \pm 0.29$.

Conclusion: This study demonstrates that elderly patients with ISH had a prevalence of concentric left ventricular hypertrophy (LVH) which was found to be more in female patients than in male patients followed by left atrial enlargement.

Keywords: Isolated systolic hypertension, Echocardiography, Left ventricular mass index, Regional wall motion abnormalities, Cardiovascular, Left ventricular hypertrophy.

(C) 2021 The Authors. Published by Innovare Academic Sciences Pvt Ltd. This is an open access article under the CC BY license (http://creativecommons.org/ licenses/by/4.0/) DOI: http://dx.doi.org/10.22159/ajpcr.2021v14i5.40546. Journal homepage: https://innovareacademics.in/journals/index.php/ajpcr

\section{INTRODUCTION}

Hypertension is the strongest or one of the strongest risk factors for almost all different cardiovascular diseases acquired during life, including coronary disease, left ventricular hypertrophy (LVH), and valvular heart diseases, cardiac arrhythmias including atrial fibrillation, cerebral stroke, and renal failure [1]. Isolated systolic hypertension (ISH) is the most common form of hypertension in the elderly and attributes to major complications than diastolic hypertension. The phenomenon of increasing systolic blood pressure (SBP) in the elderly is believed to be secondary to modifiable and hereditary risk factors as well as pathophysiological changes of ageing [2]. The public health implications of ISH are vast with respect to early treatment and reduction of development of complications like myocardial infarction (MI), heart failure, cerebrovascular accident (CVA), and retinopathy and its management still remains a challenge to practicing physicians.

ISH is defined as SBP $\geq 140 \mathrm{~mm} \mathrm{Hg}$ and a diastolic BP (DBP) of $<90 \mathrm{~mm}$ $\mathrm{Hg}$ [3]. Epidemiological study has shown that ISH is the most common form of hypertension present in approximately $2 / 3^{\text {rd }}$ of individuals more than 60 years of age [4]. The risk of cardiovascular diseases increases progressively and continuously with an increase in systolic and DBP, approximately doubling for every $20 / 10 \mathrm{~mm} \mathrm{Hg}$ incremental increase in BP that occurs within the range of 115/75-185/115 mm Hg [5]. Elevated SBP is more important than elevated DBP as a risk factor for both cardiovascular and renal disease [6]. A meta-analysis of 20 studies involving 9299 individuals and 11.1 years of follow-up showed a strong association between 24-h SBP and cardiovascular mortality, all-cause mortality, stroke, and cardiac events [7].
The main adaptation of ISH on the heart is the distensibility of the aorta and large arteries with subsequent cardiovascular events. The heart responds by increasing the wall tension and left ventricular enlargement in terms of hypertrophy and increasing myocardial contraction time. This adaptation leads to diastolic impairment with a decrease in LV compliance and early diastolic filling. Hence, patients with ISH presents with an increase in LV mass LVH compared with patients of the same age without ISH. LVH further aggravates diastolic dysfunction which is followed by an increase in pulse pressure which is a major determinant of cardiovascular complications [8-13].

ISH may occur in conditions associated with elevated cardiac output, such as anemia, hyperthyroidism, aortic insufficiency, beriberi, arteriovenous fistula, and Paget's disease of bone [14]. Age-related cardiovascular changes like atherosclerosis caused by the accumulation of arterial calcium and collagen with degradation of arterial elastin cause reduced elasticity and compliance of large arteries. With the increased stiffness of conduit arteries, the rate of return of reflected arterial pressure waves from the periphery increased, thus raising the systolic pressure. The raising SBP can promote further arterial stiffening and endothelium impairment per se [15-17].

With the improving clinical care and health facilities, the life expectancy of the population of India is increasing, thus increasing the elderly population group and incidence of ISH. Systolic hypertension in the elderly program (SHEP) trial demonstrated a $10 \%$ prevalence of ISH [18]. The Framingham heart study in the 
elderly showed that ISH was seen in $57 \%$ of men and $65 \%$ of women in the elderly [19].

The important implications of ISH on cardiovascular events can be easily carried out using echocardiography and electrocardiography (ECG) along with appropriate history and thorough investigations. The present study aims at detecting end-organ complications of ISH mainly through echocardiography in terms of LVH, regional wall motion abnormalities (RWMA), diastolic dysfunction, left atrial enlargement, and reduced ejection fraction which may manifest as coronary artery disease, MI, or congestive cardiac failure.

\section{METHODS}

An observational cross-sectional study was conducted in the Departments of General Medicine, Cardiology, and Radiodiagnosis of Maharaja Krishna Chandra Gajapati Medical College and Hospital, Berhampur, Odisha, India, for a period of 2 years from August 2018 to October 2020. Seventy patients of ISH (SBP $\geq 140 \mathrm{mmHg}$, DBP $<90 \mathrm{mmHg}$ ) were selected for study, among whom 41 were males and 29 were females with a mean age of $75.6 \pm 6.08$ years. The study population was divided into three groups according to the stages of BP; Stage I (SBP 140-159 mmHg), Stage II (SBP 160-179 mmHg), and Stage III (SBP $\geq 180 \mathrm{mmHg}$ ).

The study was conducted after the study protocol was approved by the Institutional Ethics Committee and a written and informed consent from all the patients.

All the selected patients were analyzed in terms of clinical profile, which included symptomatology, vitals measurement, clinical examination, and relevant blood investigations such as urea, creatinine, liver function tests, lipid profile, electrolytes and fundoscopy, chest X-ray, ultrasonography of abdomen, ECG, and echocardiography. Echocardiography was done in the Department of Cardiology in a color Doppler machine in 2D and $\mathrm{M}$ mode. Measurements were done using the American Society of Echocardiography (ASE) convention method. In ASE convention, the thickness of the endocardial surfaces was excluded from the measurement of left ventricular internal diameter in diastole and included in the measurement of the interventricular septum and posterior wall thickness. Ultrasonography of the abdomen was done in the Department of Radiodiagnosis to see kidney size, corticomedullary differentiation, and rule out chronic kidney disease (CKD).

\section{Inclusion criteria}

Elderly patients above the age of 65 years with SBP $>140 \mathrm{~mm} \mathrm{Hg}$ and DBP $<90 \mathrm{~mm}$ Hg were included in this study.

\section{Exclusion criteria}

Patients below the age of 65 years of age, DBP $>90 \mathrm{~mm} \mathrm{Hg}$, hypertensive patients already on antihypertensive medications, patients with secondary causes of hypertension such as CKD, renovascular, thyroid disorder, and drug-induced hypertension were excluded from this study.

\section{Statistical analysis}

The statistical analysis was done using SPSS version 16.0 for analysis of the data and Microsoft Word and Excel were used to generate graphs, tables, etc.

\section{RESULTS}

During the 2 years period of study, 70 patients of ISH were selected for study, among whom 41 were males and 29 were females with a mean age of $75.6 \pm 6.08$ years (Table 1 ). The study population was divided into three groups according to the stages of BP; Stage I (SBP 140-159 mm $\mathrm{Hg}$ ), Stage II (SBP 160-179 mm Hg), and Stage III (SBP $\geq 180 \mathrm{~mm} \mathrm{Hg}$ ). The mean age in these groups was Stage I: $73.55 \pm 6.24$ years, Stage II: $76.34 \pm 5.79$ years, and Stage III $76.5 \pm 8.39$ years (Table 2 and Fig. 1). As the age increased, the SBP also increased significantly $(\mathrm{p}=0.043) .64 .3 \%$ were asymptomatic and $37.7 \%$ were symptomatic with palpitation being the most common symptom (Fig. 2). Symptomatic patients were more in the Stage III BP $(\mathrm{p}<0.001)$.

The mean weight, height, body mass index (BMI), and body surface area (BSA) were $65.64 \mathrm{~kg}, 159.21 \mathrm{~cm}, 26.11 \mathrm{~kg} / \mathrm{m}^{2}$, and $1.67 \mathrm{~m}^{2}$, respectively (Table 3). BSA is significantly more in the females with $p<0.001$. Average BMI is more in females $\left(27.15 \mathrm{~kg} / \mathrm{m}^{2}\right)$ than in male counterparts $(25.38$ $\left.\mathrm{kg} / \mathrm{m}^{2}\right)$ (Fig. 3a and b) ( $\left.\mathrm{p}=0.097\right)$.

\section{ECG and echocardiographic findings}

About $37 \%$ of the patients had ECG-LVH as per Sokolow-Lyon positive criteria (SV1 \pm RV5 $/ 6>35 \mathrm{~mm}$ ). About $30 \%$ of the patients had ECG-LVH as per Romhilt-Estes score criteria (score $>5$ ) (Table 4 and Fig. 4).

In the present study, echocardiographic changes seen were increased left ventricular mass index (LVMI) in $45.71 \%$, increased $\mathrm{LV}$ volume $\left(>90 \mathrm{ml} / \mathrm{m}^{2}\right)$ in $1857 \%$ and $27.1 \%$ were having reduced ejection fraction $(<56 \%)$ and $30 \%$ presented with RWMA (Table 5 and Fig. 5).

As the stages of BP increased the incidence of increased LVMI increased. Patients presenting with stage III BP were 2.26 times more likely to develop increased LVMI with $\mathrm{p}=0.04$. In the current study, it was observed that female patients were more likely to develop increased LVMI compared to male counterparts $(\mathrm{p}=0.021)$. About $16.2 \%$ of the patients in Stage I BP, 34.8\% in Stage II, and $38.9 \%$ in Stage III were having increased LV mass (Table 6).

Of 70 patients, 28 patients developed retinal changes. About 13.3\% for focal arteriolar narrowing, $12 \%$ had arteriovenous nipping, and about $8 \%$ developed retinopathy. Among retinopathy patients, grade I retinopathy in $12 \%$, grade II retinopathy in $17 \%$, grade III retinopathy in $10 \%$, and grade IV retinopathy in $1.43 \%$. Cataract developed in $31.43 \%$ of patients. Patients with stage III BP were found to be more likely to develop abnormal retinal changes (Table 7 and Fig. 6).

In the present study, left atrial size was significantly increased in $52.66 \%$ of the patients. Patients with Stage III BP had 62\% with LA enlargement as compared to $51 \%$ in Stage II and $45 \%$ in Stage I. Hence, as SBP increased, the prevalence of LA enlargement increased (Table 8 and Fig. 7).

Doppler measurements of diastolic filling were significant in patients with systolic hypertension with higher peak atrial velocity (A wave) with $79.71 \pm 11.79 \mathrm{~cm} / \mathrm{s}$ and a lower ratio of peak early to atrial velocity was $0.82 \pm 0.29$ (Table 9 and Fig. 8).

In the current study, diastolic filling was altered in patients with ISH with an increase in peak atrial velocity and a reduced E/A ratio.

Table 1: Age and gender distribution

\begin{tabular}{|c|c|c|c|c|c|c|}
\hline Age in years & Female & Percentage & Male & Percentage & Total & Total percentage \\
\hline$<65$ & 2 & 6.9 & 3 & 7.32 & 5 & 7.1 \\
\hline $65-70$ & 6 & 20.69 & 9 & 21.95 & 15 & 21.42 \\
\hline $71-75$ & 5 & 17.24 & 10 & 24.39 & 15 & 21.42 \\
\hline $76-80$ & 9 & 31.03 & 9 & 21.95 & 18 & 25.71 \\
\hline $81-86$ & 4 & 13.79 & 6 & 14.63 & 10 & 14.28 \\
\hline$>85$ & 3 & 10.34 & 4 & 9.76 & 7 & 10 \\
\hline Total & 29 & 100 & 41 & 100 & 70 & 100 \\
\hline Mean \pm SD & $76.06 \pm 6.65$ & & $75.26 \pm 7.24$ & & & \\
\hline
\end{tabular}


Table 2: Correlation of age with stages of blood pressure ( $\mathrm{mmHg}$ )

\begin{tabular}{|c|c|c|c|c|c|c|}
\hline \multirow[t]{2}{*}{ Age group in years } & \multicolumn{2}{|c|}{ Stage I: (140-159) mmHg } & \multicolumn{2}{|c|}{ Stage II: (160-179) mmHg } & \multicolumn{2}{|c|}{ Stage III: $(>180) \mathrm{mmHg}$} \\
\hline & Number & Percentage & Number & Percentage & Number & Percentage \\
\hline$<65$ & - & - & 1 & 3.44 & 4 & 19.05 \\
\hline $71-75$ & 7 & 35 & 7 & 24.14 & 1 & 4.76 \\
\hline $76-80$ & 1 & 5 & 10 & 34.48 & 7 & 33.33 \\
\hline $81-85$ & 2 & 10 & 6 & 20.69 & 2 & 9.52 \\
\hline$>85$ & 2 & 10 & 1 & 3.45 & 4 & 19.05 \\
\hline Total & 20 & 100 & 29 & 100 & 21 & 100 \\
\hline Mean \pm SD & $73.55 \pm 6.24$ & & $76.34 \pm 5.79$ & & $76.5 \pm 8.39$ & \\
\hline
\end{tabular}

Table 3: Anthropometry

\begin{tabular}{|c|c|c|c|}
\hline Anthropometry & $\begin{array}{l}\text { Females } \\
(\text { Mean } \pm \text { SD) }\end{array}$ & $\begin{array}{l}\text { Males } \\
(\text { Mean } \pm \text { SD) }\end{array}$ & $P$ value \\
\hline Weight (in kg) & $63.03 \pm 7.49$ & $67.49 \pm 11.21$ & 0.067 (NS) \\
\hline Height (in $\mathrm{cm}$ ) & $153 \pm 8.84$ & $163.61 \pm 10.87$ & $<0.001(\mathrm{~S})$ \\
\hline $\begin{array}{l}\text { Body mass index } \\
\left(\text { in } \mathrm{kg} / \mathrm{m}^{2}\right)\end{array}$ & $27.15 \pm 4.25$ & $25.38 \pm 4.4$ & 0.097 (NS) \\
\hline $\begin{array}{l}\text { Body surface } \\
\text { area }\left(\text { in } m^{2} \text { ) }\right.\end{array}$ & $1.6 \pm 0.11$ & $1.73 \pm 0.17$ & $<0.001(\mathrm{~S})$ \\
\hline
\end{tabular}

Table 4: Electrocardiographic changes regarding left ventricular hypertrophy

\begin{tabular}{lll}
\hline Electrocardiographic $(\mathbf{n}=\mathbf{7 0})$ & Number & Percentage \\
\hline Sokolow - Lyons positive $(>35 \mathrm{~mm})$ & 26 & 37 \\
Romhilt - Estes scores $(>5$ points $)$ & 21 & 30 \\
\hline
\end{tabular}

Table 5: Echocardiographic findings in isolated systolic hypertension

\begin{tabular}{lll}
\hline Echo changes $(\mathbf{n}=\mathbf{7 0})$ & Cases & Percentage \\
\hline Increased left ventricular mass index (males & 32 & 45.71 \\
$>131 \mathrm{~g} / \mathrm{m}^{2}$, females $\left.>100 \mathrm{~g} / \mathrm{m}^{2}\right)$ & & \\
Increased left ventricular volume $\left(>90 \mathrm{ml} / \mathrm{m}^{2}\right)$ & 13 & 18.57 \\
Reduced ejection fraction $(<56 \%)$ & 19 & 27.1 \\
Regional wall motion abnormality & 21 & 30 \\
\hline
\end{tabular}

Table 6: Association of left ventricular mass index with stages of blood pressure

\begin{tabular}{lllll}
\hline $\begin{array}{l}\text { Stage of } \\
\text { blood } \\
\text { pressure }\end{array}$ & $\begin{array}{l}\text { Increased left } \\
\text { ventricular mass } \\
\text { index }(\mathbf{n}=\mathbf{4 3})\end{array}$ & $\begin{array}{l}\text { Normal } \\
\mathbf{( n = 2 7 )}\end{array}$ & p value & OR \\
\hline Stage I & $7(16.2 \%)$ & $10(37.0 \%)$ & 0.004 & 0.33 \\
Stage II & $15(34.8 \%)$ & $9(33.3 \%)$ & 0.321 & 1.07 \\
Stage III & $21(21 \%)$ & $8(29.6 \%)$ & 0.044 & 2.26 \\
\hline
\end{tabular}

Table 7: Stages of blood pressure with retinal changes

\begin{tabular}{llllll}
\hline $\begin{array}{l}\text { Fundus } \\
\text { grade }\end{array}$ & Stage I & Stage II & Stage III & $\begin{array}{l}\text { Total } \\
\mathbf{n = 7 0}\end{array}$ & Percentage \\
\hline Normal & 7 & 7 & 5 & 19 & 27.14 \\
Grade I & - & 6 & 3 & 9 & 12.86 \\
Grade II & 4 & 4 & 4 & 12 & 17.14 \\
Grade III & 2 & 3 & 2 & 7 & 10 \\
Grade IV & - & - & 1 & 1 & 1.43 \\
Cataract & 7 & 9 & 6 & 22 & 31.43 \\
\hline
\end{tabular}

\section{DISCUSSION}

ISH is highly prevalent in the elderly and is a major cause of morbidity and mortality [2]. In persons older than 50 years, SBP of more than
Table 8: Stages of blood pressure with left atrial enlargement

\begin{tabular}{lll}
\hline Stages of blood pressure & $\begin{array}{l}\text { LA size (in mm) } \\
\text { Mean } \pm \text { SD }\end{array}$ & Percentage \\
\hline Stage I & $36.11 \pm 3.58$ & 45 \\
Stage II & $36 \pm 2.65$ & 51 \\
Stage III & $36.48 \pm 3.21$ & 62 \\
\hline
\end{tabular}

Table 9: Stages of blood pressure with E/A ratio

\begin{tabular}{llll}
\hline Stages & MEAN \pm SD & & E/A ratio \\
\cline { 2 - 3 } & E wave $(\mathbf{c m} / \mathbf{s})$ & A wave $(\mathbf{c m} / \mathbf{s})$ & \\
\hline Stage I & $66.78 \pm 6.64$ & $79.61 \pm 7.96$ & $0.85 \pm 0.18$ \\
Stage II & $64.91 \pm 6.26$ & $79.91 \pm 4.93$ & $0.81 \pm 0.06$ \\
Stage III & $65.52 \pm 8.5$ & $79.54 \pm 6.19$ & $0.82 \pm 0.13$ \\
\hline
\end{tabular}

$140 \mathrm{~mm} \mathrm{Hg}$ is a much more cardiovascular risk factor than DBP and needs to be looked out while treating hypertension.

ISH according to age and sex

In the present study, 41 males and 29 females were taken and the prevalence of ISH was found to be significantly more in the age group of 71-80 years. Comparing the present study with another study by Diwedi et al., the mean age was found to be $(67.36 \pm 6.23)$ years and range was 60-90 years with male to female ratio 1.44:1 [20]. SHEP trial [18] found a mean age of 72 years and mean BP 170/77 mm Hg. Colandrea et al. found mean age 69.7 years [21]. Bharucha and Kuruvilla [22] found the proportion of hypertensives suffering from ISH increased with age in those more than 70 years. About $75.6 \%$ of men and $82.1 \%$ of women with hypertension had ISH [22]. This was found to be significantly more in women than in men. In the present study, female were more prone for ISH.

\section{ISH according to stages and age}

The current study shows as the age increases, the SBP also increases significantly $(\mathrm{p}<0.001)$. The mean age at stage I BP was found to be $(73.55 \pm 6.24)$ years, the mean age at stage II BP was $76.34 \pm 5.79$ years, and the mean age at stage III BP was found to be $(76.5 \pm 8.39)$ years. Messerli et al. found a prevalence of ISH increased with age from about $5 \%$ of the persons at 60 years to $25 \%$ of those at 80 years [23]. Rocha and Mello e Silva found that there had been an increase in ISH from $44 \%$ to $57 \%$ in the age group from 60 to 80 years [24].

\section{Symptomatology}

Although most patients were asymptomatic, among those who developed symptoms, the most common symptom was found to be palpitation $(20 \%)$. Stage III BP group constituted more of the symptomatic patients. Kulkarni et al. found that $32 \%$ were asymptomatic and among the symptomatic cases, headache was a common presentation (77.9\%) [25]. However, the age group in their study ranged from 60 to 65 years, whereas, in the present study, it ranged from 65 to 90 years. 


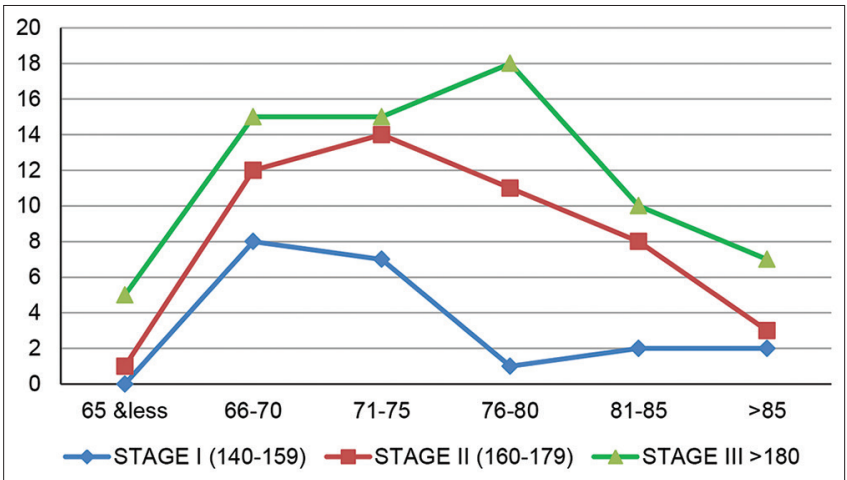

Fig. 1: Age with blood pressure $(\mathrm{mmHg})$ as the age increased, the blood pressure also increased significantly with $\mathrm{p}<0.043$

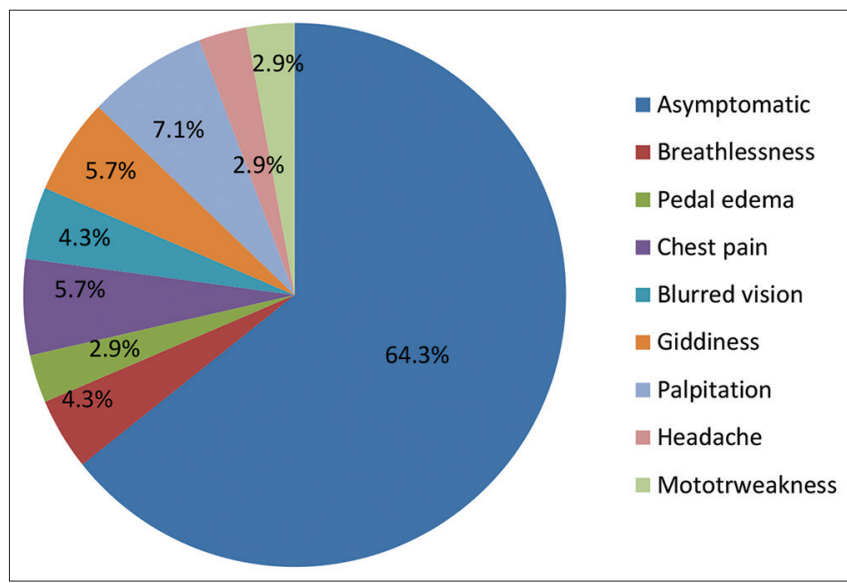

Fig 2: Symptomatology $64.3 \%$ were asymptomatic and $35.7 \%$ were symptomatic, with palpitation being the most common symptom. Symptomatic patients were more in stage III blood pressure group with $\mathbf{p}<0.001$

\section{Anthropometry}

In the present study, average weight for female was $63.03 \pm 7.4 \mathrm{~kg}$, average BMI was $27.15 \pm 4.25 \mathrm{~kg} / \mathrm{m}^{2}$ compared to male weight of $67.49 \pm 11.21 \mathrm{~kg}$, and BMI $25.38 \pm 4.4 \mathrm{~kg} / \mathrm{m}^{2}$. Wilking et al. found that age and obesity in women were significant variables in the evolution of ISH [4].

\section{Retinal change}

Of 70 patients, 28 patients developed retinal changes. About 13.3\% had focal arteriolar narrowing, $12 \%$ had arteriovenous nipping, and about $8 \%$ developed retinopathy with Grade I retinopathy in $12 \%$, Grade II retinopathy in 17\%, Grade III retinopathy in 10\%, and Grade IV retinopathy in $1.43 \%$. Cataracts developed in $31.43 \%$ of patients. Patients with Stage III BP were found to be 2.18 times more likely to develop abnormal retinal changes. Wong et al. in his study found that retinal microvascular abnormality was $8.3 \%$ for retinopathy, 9.6\% for focal arteriolar narrowing, and $7.7 \%$ for arteriovenous nipping [26].

\section{Electrocardiographic changes}

The most common ECG finding seen in the present study was LVH, mainly Sokolow-Lyon positive ( $>35 \mathrm{~mm}$ ) in $37 \%$ of the patients and Romhilt-Estes score ( $>5$ points) in $30 \%$ of the patients. The other findings were left arterial enlargement, lateral wall ischemia, anteroseptal wall ischemia, inferolateral wall, and septal wall ischemia. Vrinda et al. found that LVH was the most common ECG manifestation in $36.8 \%$ of the patients. Boon found a prevalence of silent myocardial ischemia in ISH [27].

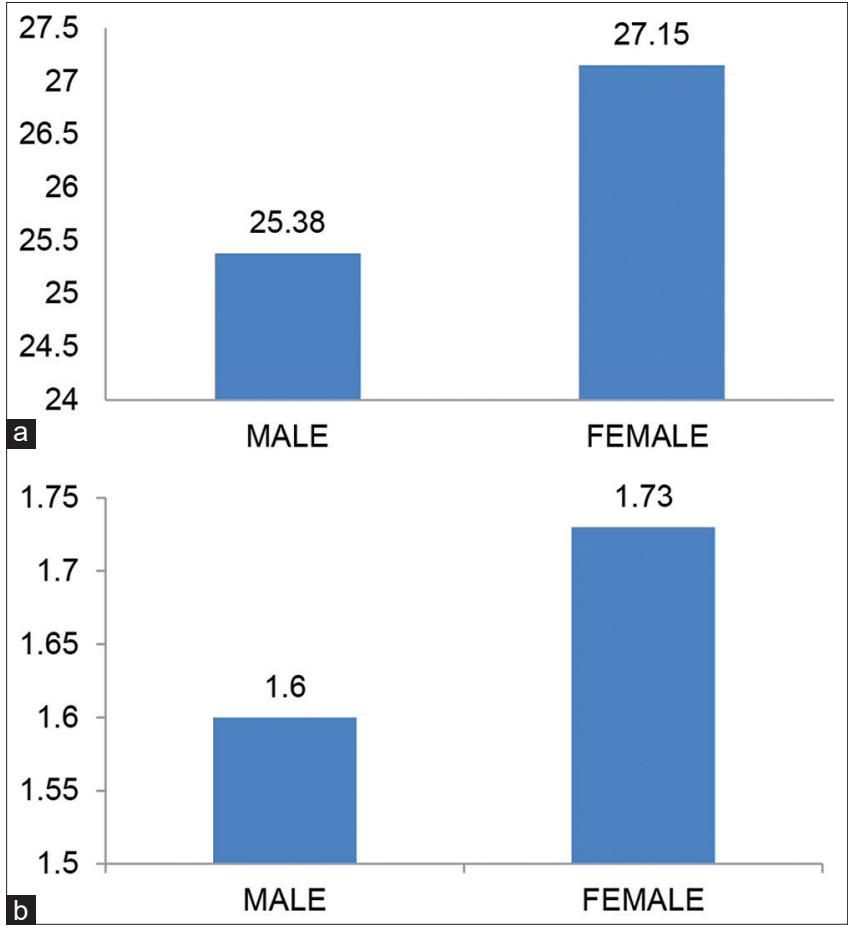

Fig. 3: (a) Body mass index (in $\mathrm{kg} / \mathrm{m}^{2}$ ) and sex (b) body surface area (BSA) (in $\mathrm{m}^{2}$ ) and sex. BSA was significantly more in the females with $p<0.001$. Average body mass index was $27.15 \mathrm{~kg} / \mathrm{m}^{2}$ in females and male counterparts average was $25.38 \mathrm{~kg} / \mathrm{m}^{2}$. $\mathbf{p}=\mathbf{0 . 0 9 7}$ (not significant)

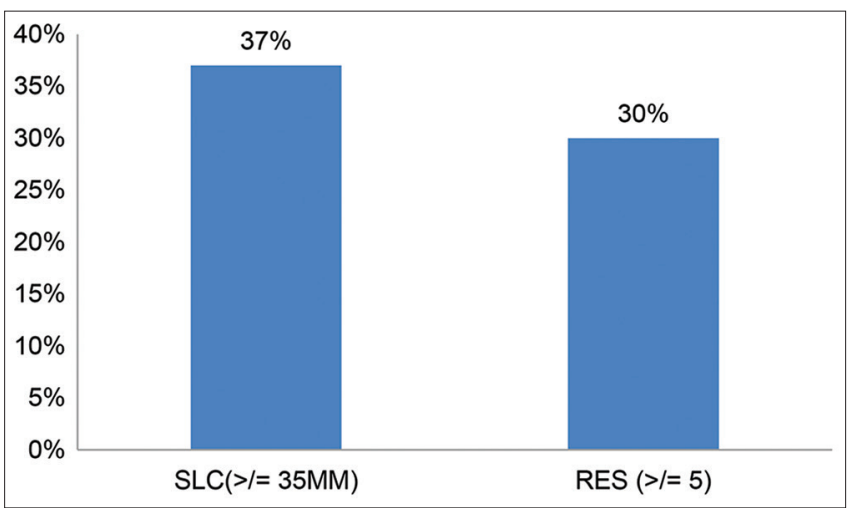

Fig. 4: Percentage of left ventricular hypertrophy

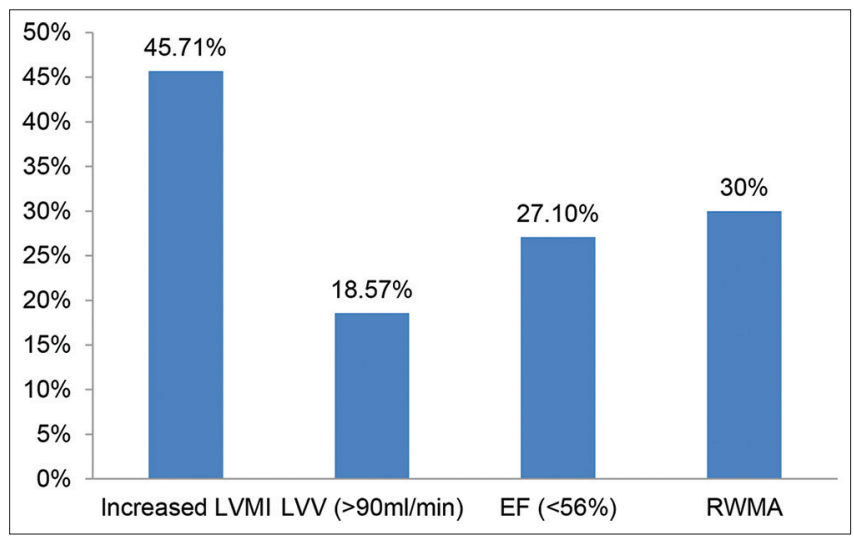

Fig. 5: Echo findings 


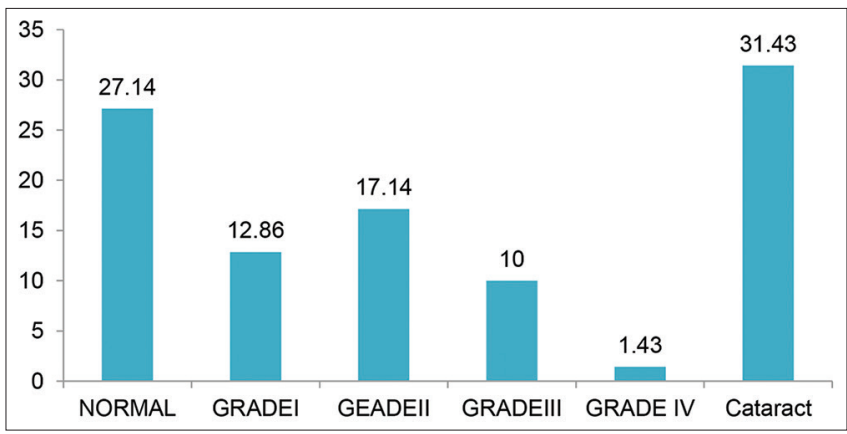

Fig. 6: Retinal changes

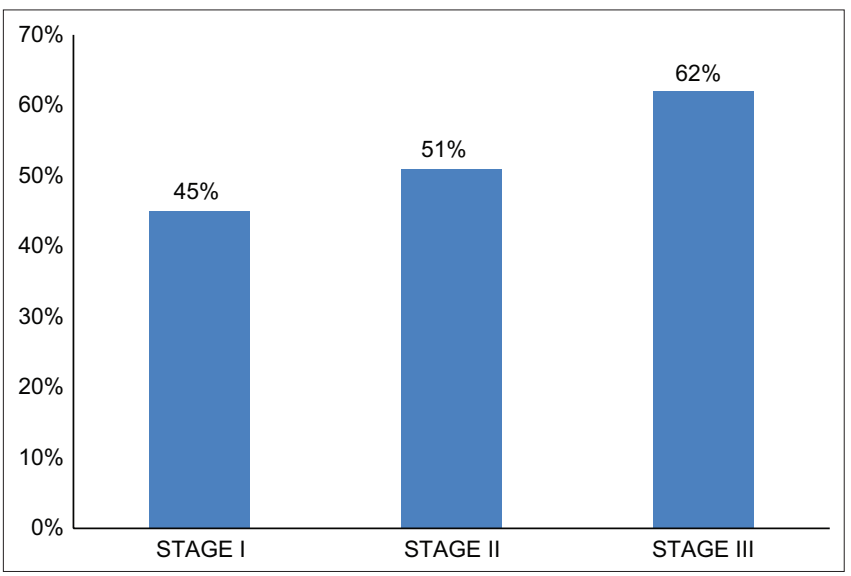

Fig. 7: LA Enlargement (\%)

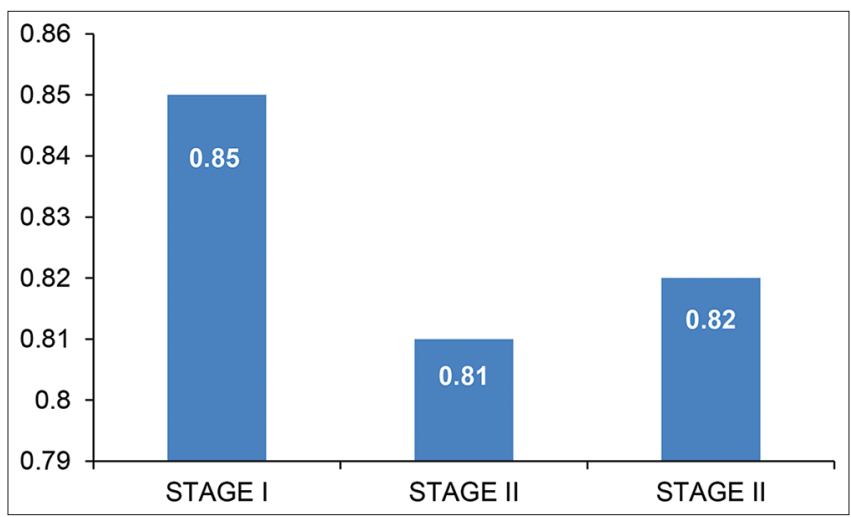

Fig. 8: Stages of blood pressure with E/A Ratio

\section{Echocardiographic changes}

Association of stages of BP with increased LVMI

It is observed in the present study that $16.2 \%$ of the patients in Stage I BP, $34.8 \%$ of the patients in Stage II, and 38.9\% in Stage III BP were having increased LV mass. It is observed that as the stage of BP increases, incidence of LV mass also increases significantly $(\mathrm{p}=0.04$.) It is also observed that female patients are more likely to develop increased LVMI compared to male patients.

\section{LVH and ISH}

The cardiac adaptation to combined systolic and diastolic hypertension is studied primarily by M mode echocardiography. The major finding was an increase in wall thickness leading to concentric LVH. Savage et al. using M - mode echocardiography, demonstrated abnormally increased ventricular septal wall thickness or posterior wall thickness or both in $61 \%$ and abnormally increased left ventricular mass in $51 \%$ of asymptomatic subjects with mild to moderate diastolic hypertension [28]. In Chatterjee et al. study, echocardiography detected LVH to be $36 \%, 68 \%$, and $80 \%$ in Stage I, Stage II, and Stage III female patients and $30 \%, 58 \%$, and $70 \%$ in the same stage male patients [29]. Schlant et al. found increased left ventricular mass in $49 \%$ of their hypertensive patients. This adaptation occurs to maintain cardiac output in the setting of increased afterload [30]. In the present study, patients with ISH developed LVH in a similar fashion, with a significant increase in ventricular septal and posterior wall thickness resulting in increased LV mass. SHEP trial also showed increased LVH in ISH and also as the predictor of fatal outcome [18].

\section{Left atrial size and ISH}

In the present study, left atrial size was significantly increased where $52.66 \%$ of the patients had left atrial enlargement. Savage et al. observed an abnormally increased left atrial dimension in only $5 \%$ of their hypertensive patients [28]. Chatterjee $e t$ al. found one significant anatomic abnormality as mean LA enlargement of $3.37 \mathrm{~cm}$ (range 2.7-4.7 $\mathrm{cm}$ ) showing slightly higher mean value than that of their control group which was $3.08 \mathrm{~cm}$ and correlates well with our present study (Table 8). However, LA enlargement $>4 \mathrm{~cm}$ was detected in $8 \%, 18 \%$, and $32 \%$ in Stage I, Stage II, and Stage III patients, respectively, and $8 \%$ in their control group [29]. Dunn et al. found a significantly higher left atrial size only in hypertensive patients with left atrial abnormality or LVH on ECG [31]. The result of the present study suggests that left atrial enlargement occurs secondary to ageing and may be accelerated by the presence of ISH. This phenomenon may be secondary to the abnormal diastolic function that has been demonstrated with both ageing and hypertension.

\section{Diastolic function and ISH}

Diastolic function as measured by Doppler echocardiographic filling variables is affected very early in diastolic hypertension and frequently precedes the development of overt LVH. In the current study, diastolic filling was altered in patients with ISH, with an increase in peak atrial velocity and a reduced $\mathrm{E} / \mathrm{A}$ ratio.

\section{CONCLUSION}

This study demonstrates that elderly patients with ISH had a prevalence of concentric LVH which was found to be more in female patients than in male patients followed by left atrial enlargement. ISH is the most common cause of high BP in the elderly. The incidence increases with age advancement. It is an even better predictor of morbidity and mortality than in DBP. Several large clinical trials have documented a clear benefit of treating ISH. Even small reduction in BP has a substantial outcome. Hence, to prevent cardiovascular mortality and morbidity in the elderly with ISH, early detection and treatment are essential.

\section{AUTHORS' CONTRIBUTIONS}

The authors declare that all the named authors have contributed equally to this article.

\section{CONFLICTS OF INTEREST}

The authors have no conflicts of interest to disclose.

\section{FUNDING}

No funding sources.

\section{REFERENCES}

1. Kjeldsen SE. Hypertension and cardiovascular risk: General aspects. Pharmacol Res 2018;129:95-9.

2. Bavishi C, Goel S, Messerli FH. Isolated systolic hypertension: An update after SPRINT. Am J Med 2016;129:1251-8.

3. Manicia G, Fagard R, Narkiewicz K, Redon J,Zanchetti A, Böhm M, et al. 2013 ESH/ESC guidelines for the management of arterial hypertension: The Task Force for the Management of Arterial Hypertension of the European Society of Hypertension (ESH) and of the European Society of Cardiology (ESC). Eur Heart J 2013;34:2159-219.

4. Wilking SV, Belanger A, Kannel WB, D'Agostino RB, Steel K. 
Determinants of isolated systolic hypertension. JAMA 1988; 260:3451-5.

5. Lewington S, Clarke R, Qizilbash N, Peto R, Collins R. Age-specific relevance of usual blood pressure to vascular mortality: A meta-analysis of individual data for one million adults in 61 prospective studies Lancet 2002;360:1903-13.

6. Izzo JL, Levy D, Black HR. Importance of systolic blood pressure in older Americans. Hypertension 2000;35:1021-4.

7. Conen D, Bamberg F. Noninvasive 24-h ambulatory blood pressure and cardiovascular disease: A systematic review and meta-analysis. J Hypertens 2008;26:1290-9.

8. Franklin SS, Khan SA, Wong ND, Larson MG, Levy D. Is pulse pressure useful in predicting risk for coronary heart disease? The Framingham heart study. Circulation 1999;100:354-60.

9. London GM, Guerin AP. Influence of arterial pulse and reflected waves on blood pressure and cardiac function. Am Heart J 1999;138:220-4.

10. Boutioukos M, Schinkel AF, Bax JJ, Lampropoulos S, Poldermans D. The impact of hypertension on systolic and diastolic left ventricular function. A tissue Doppler echocardiographic study. Am Heart J 2006;151:1323.

11. Heesen WF, Beltman FW, May JF, Smit AJ, de Graeff PA, Havinga TK, et al. High prevalence of concentric remodeling in elderly individuals with isolated systolic hypertension from a population survey. Hypertension 1997;29:539-43

12. Sumimoto T, Murakami E, Iwata T, Dazai Y, Hiwada K. Left ventricular cardiac structure and diastolic function in isolated systolic hypertension in the elderly. J Hum Hypertens 1993;7:3-6.

13. Asmar R, Rudnichi A, Blacher J, London GM, Safar ME. Pulse pressure and aortic pulse wave are markers of cardiovascular risk in hypertensive populations. Am J Hypertens 2001;14:91-7.

14. Chobanian AV, Bakris GL, Black HR, Cushman WC, Green LA, Izzo JL, et al. Seventh report of the Joint National Committee on Prevention, Detection, Evaluation, and Treatment of High Blood Pressure. Hypertension 2003;42:1206-52

15. Yambe M, Tomiyama H, Yamada J, Koji Y, Motobe K, Shiina K, et al. Arterial stiffness and progression to hypertension in Japanese male subjects with high normal blood pressure. J Hypertens 2007;25:87-93.

16. Zieman SJ, Melenovsky V, Kass DA. Mechanisms, pathophysiology, and therapy of arterial stiffness. Arterioscler Thromb Vasc Biol 2005;25:932-43

17. Lind L. Systolic and diastolic hypertension impair endothelial vasodilatory function in different types of vessels in the elderly: The Prospective Investigation of the Vasculature in Uppsala Seniors (PIVUS) study. J Hypertens 2006;24:1319-27.

18. Prevention of stroke by antihypertensive drug treatment in older persons with isolated systolic hypertension. Final results of the Systolic Hypertension in the Elderly Program (SHEP). SHEP Cooperative Research Group. JAMA 1991;265:3255-64.

19. Kannel WB, Castelli WP, McNamara PM, McKee PA, Feinleib M. Role of blood pressure in the development of congestive heart failure. The Framingham study. N Engl J Med 1972;287:781-7.

20. Dwivedi S, Singh G, Agarwal MP. Profile of hypertension in elderly subjects. J Assoc Physicians India 2000;48:1047-9.

21. Colandrea MA, Gary D Systolic hypertension in the elderly. An epidemiologic assessment of circulation. Am J Med 1991;90:145-205.

22. Bharucha NE, Kuruvilla T. Hypertension in the Parsi community of Bombay: A study on prevalence, awareness and compliance to treatment. BMC Public Health 2003;3;1.

23. Messerli FH. Hypertension in special populations. Med Clin North Am 1997;81:1335-45.

24. Rocha E, Mello e Silva A. Isolated systolic hypertension--epidemiology and impact in clinical practice. Rev Port Cardiol 2003;22:7-23.

25. Kulkarni V, Bhagwat N, Hakim A, Kamath S, Soneji SL. Hypertension in the elderly. J Assoc Physicians India 2001;49:873-6.

26. Wong TY, Klein R, Sharrett AR, Manolio TA, Hubbard LD, Marino EK, et al. The prevalence and risk factors of retinal microvascular abnormalities in older persons: The Cardiovascular Health Study. Ophthalmology 2003;110:658-66.

27. Boon D. ST segment depression criteria and the prevalence of silent cardiac ischemia in hypertensives. Hypertension 2003;4:476-81.

28. Savage DD, Drayer JI, Henry WL, Mathews EC, Ware JH, Gardin JM, et al. Echocardiographic assessment of cardiac anatomy and function in hypertensive subjects. Circulation 1979;59:623-32.

29. Chatterjee S, Roy AN, Majumdar BB, Ghosh S, Bala B, Bhowmick K, et al. Changes in cardiac status due to isolated systolic hypertension by non-invasive studies. J Evol Med Dent Sci 2014;3:347-55.

30. Schlant RC, Gilbert CA, Nutter DO. Echocardiographic study of cardiac dimensions and function in the endurance-trained athlete. Am J Cardiol 1977;40:528-33.

31. Dunn FG, Chandraratna P, De Caralho JG, Basta LL, Frohlich ED. Sudden cardiac death, ventricular arrhythmias and hypertensive left ventricular hypertrophy. J Hypertens 1993;11:1003-10. 